\title{
Introduction
}

\section{Anthropological Knowledge and Practice in Global Health}

\section{Rodney Reynolds and Isabelle L. Lange}

\begin{abstract}
Авstract: Since the turn of the millennium, conceptual and practice-oriented shifts in global health have increasingly given emphasis to health indicator production over research and interventions that emerge out of local social practices, environments and concerns. In this special issue of Anthropology in Action, we ask whether such globalised contexts allow for, recognise and sufficiently value the research contributions of our discipline. We question how global health research, ostensibly inter- or multi-disciplinary, generates knowledge. We query 'notknowing' practices that inform and shape global health evidence as influenced by funders' and collaborators' expectations. The articles published here provide analyses of historical and ethnographic field experiences that show how sidelining anthropological contributions results in poorer research outcomes for the public. Citing experiences in Latin America, Angola, Senegal, Nigeria and the domain of global health evaluation, the authors consider anthropology's roles in global health.
\end{abstract}

KEYWORDs: anthropology, global health, qualitative methods, research methodology, knowledge, public

He began to realize that the way Conrad's Master Mariners came to terms with their imagination - denying it any expression but projecting it all on to the sea which they then faced as though it were simultaneously their personal justification and their personal enemy - was not suitable for a doctor in his position. He had done just that - using illness and medical dangers as they used the sea. He began to realize that he must face his imagination, even explore it. It must no longer lead always to the 'unimaginable', as it had with the Master Mariners contemplating the possible fury of the elements - or, as in his case, to his contemplating only fights within the jaws of death itself. (The clichés are essential to the vision.) He began to realize that imagination had to be lived with on every level: his own imagination first - because otherwise this could distort his observation - and then the imagination of his patients.

$$
\text { - John Berger and Jean Mohr, A Fortunate Man: }
$$
The Story of a Country Doctor
An anthropologist within his own scientific field will use the knowledge he acquires by research to solve anthropological problems and these may have no practical significance whatever. It may be held that it is laudable for an anthropologist to investigate practical problems. Possibly it is, but if he does so he must realise that he is no longer acting within the anthropological field but in the non-scientific field of administration. Of one thing I feel quite certain: that no one can devote himself wholeheartedly to both interests; and I doubt whether anyone can investigate fundamental and practical problems at the same time.

- E. E. Evans-Pritchard, 1946

John Berger's text, quoted in the first epigraph above and taught in medical anthropology courses worldwide, with its eponymous 'fortunate man', follows the story of a country doctor. He treats his patients and by doing so confronts medical uncertainty as 
well as his own limitations. For him, the unimaginable referred to in the text suggests not only an unwanted patient outcome, but, more specifically, an outcome so horrible that it could only exist if what one conjures in nightmares were true.

Imagining the unimaginable or confronting the nightmare' means documenting, learning from and living with the varied ways in which people experience that nightmare, just as Berger's fortunate man did. How the people who enable, inform and populate our research engage with what ails them gives evidence to that which matters in their worlds. But does contemporary global health permit itself to document and tell that story and then subsequently allow such experiences to inform global health research and interventions?

For many around the globe, the nightmare is an opportunity-restricted life complicated by poverty, disease, isolation from medical services, and poor health. While metrics, along with testimonies of hardship and suffering punctuated with occasional successes, may get communicated within global health narratives, what gets unintentionally left out or intentionally excluded? The hero of Berger's book underscores the idea that to face and explore both the imagination and the nightmare means struggling less with the inevitability of mortality than it does with exploring how people live with and face misfortune, disease and illness. Sometimes sitting with a patient's family over a cup of tea matters more than applying yet another treatment or procedure (Berger and Mohr 1967). Sometimes, for an academic researcher, listening to and sharing the hopes that a mother has for the life of her Zika-affected child matters more than offering descriptions of policy pathways for mosquito eradication strategies.

For many lives mired in 'the nightmare', the process of waking from it as well as the nightmare of living reduced lives manifests as equally unimaginable for researchers in global health studies via both qualitative and quantitative representations. These nightmare facts find expression in global health's representations as the rationale for global health interventions and for its multi-disciplinary research projects - even as researchers who often live at a distance from the places and problems they study may find such problems unrelatable to their own lives. If indeed global health organises itself around a core problem, it arguably intends to frame unimaginable health concerns in terms of practical interventions that might address them. While no consensus exists about how to do that, we ask in this special issue what role anthropology might assume in constituting one.
Recently, at the Edinburgh Valuing Health Conference 2018, Christopher Davis asked: How can a researcher adequately testify with numbers or in writing about a mother made to face her own death and that of her newly born twins as a consequence of blood loss and uterine rupture while giving birth? How does one represent the aftermath of such personal and communal loss in a maternal health model or engage meaningfully with those who would argue that such considerations should not inform models? How does one give proper significance to the all-encompassing wail of grief that erupts from the village so overwhelmed by loss that no other sounds perceptibly penetrate the settlement?

We can easily relate the fact that the village's location would require three hours travel upriver by boat to reach the closest medical facility. As for the rest, do we simply drop such knowledge from our accounts even when we know it matters for grasping the nature of the problems we hope our work addresses (Prince and Marsland 2014)? Davis (2018) poses the same problem that we point to with reference to Berger's text and its utility in teaching anthropological awareness. How do we make sense of entangled subject ontologies and interpret their tension through the practical work of doing anthropology and enabling health interventions, all without finding ourselves merely operating in the 'non-scientific field of administration' (Evans-Pritchard 1946: 93)?

This special issue emerges from discussions we had after the panel we organised in 2015 for the European Association for Social Anthropology's (EASA) Medical Anthropology MAGic conference held at the University of Sussex in the United Kingdom. Each of the authors whose work appears here found themselves unexpectedly questioning how 'doing anthropology' as part of global health projects challenges underlying assumptions about the relationship between anthropology and contemporary global health concepts and practices.

\section{Assumptions}

We do not reprise here debates about how anthropologists define global health (for example, Janes and Corbett 2010; Kleinman 2010; and Nguyen 2016); neither do we make the reductive argument that anthropology brings value to global health primarily as a method for conducting formative research or evaluation; nor do we explicitly explore anthropology's long history of critical engagement with numbers and statistics (for example, Asad 1994; Erikson 
2012; Merry and Conley 2011). Instead, we recognise that contemporary global health's need to capture information, link researchers and practitioners more effectively to one another, and to increase financial resources has occasioned shifts within global health practice over the past decade away from gathering and analysing data for the purpose of redressing local inequalities and moved instead towards producing indicators to meet funders' needs (Adams 2013; Storeng and Béhague 2017). But where does that leave anthropology?

Though not mutually exclusive, the shifts in practice and concepts that have occurred within global health over the past 20 years have taken place independently of how anthropological theory and applied/ practical anthropology have also changed during the same period (and before). Paul Farmer's Pathologies of Power (2003) stands as a conceptual and physical artefact of this shift. The essays it contains emphasise how anthropologists and physicians work with local people and within communal movements. They help conduct human and professional resources to focus on issues of concern that local people identify as most relevant. Farmer's work demonstrated how people's health concerns often exemplify their need for greater social justice as opposed to more effective measurement and representation of their vulnerabilities.

Significantly, Farmer's Pathologies of Power also sits comfortably and explicitly within at least 100 years of anthropological practice that has employed ethnography to reveal the intangible (power, poverty) but material through description and critical analysis of the tangible circumstances of people's experiences of their everyday lives as involved with the anthropologist and anthropological conceits. As anthropologists, we do ethnography. And as Laura Nader (2011: 211; emphasis in the original) put it, '[e]thnography, whatever it is, has never been mere description. It is also theoretical in its mode of description. Indeed, ethnography is a theory of description'. But as E.E. Evans-Pritchard wrote in his short 1946 appeal (referenced above) for more anthropological resources in the United Kingdom, anthropologists should concern themselves mostly with anthropological problems. If anthropologists do ethnography, and we do or apply anthropology through our practices of description, how do we do ethnography while working explicitly within the domain of global health that does not regularly embrace ethnography? If ethnography is 'a theory of description', what would it actually describe in global health?

Our anthropological education trained us to ask 'what will constitute data?' as the first concern of fieldwork (the basis of our ethnography). George Marcus and Dick Cushman (1982: 27) contextualise Nader and 'define an ethnography simply as an account resulting from having done fieldwork ... so evidence of fieldwork, however written into a text, marks a work as ethnography'. To the extent that participation in global health research permits anthropologists to define what will constitute data and then generate theory from their descriptions of gathering that data utilising some form of fieldwork, we will have engaged with a question anthropologically and so too will have done anthropology. Accordingly, an older (and for some a seductive) anthropology such as that represented by Evans-Pritchard's quote above in the second epigraph, in which only fundamental and specific questions would lend themselves to anthropological and scientific investigation, we can set aside. We can also set aside debates about method or the specific theoretical grounding or approach to the kind of anthropology that we practice.

We cannot, however, set aside the problems presented by anthropologists working in global health asking, 'what will constitute ethnographic data?', because a certain empirical concreteness seems to frame the acceptable response, more often than not, in terms of what targeted informants in the field say in formal encounters. This is despite knowing that anthropological and ethnographic knowledge often arises through informal encounters and in unanticipated ways (Last, this issue). If an anthropologist begins any project by asking 'what will constitute ethnographic data?', what can constitute data in global health for the anthropologist - especially one who works in multi-disciplinary teams whose data constructs and project requirements may not embrace ethnography? How do global health projects treat data that may question or challenge the empiricist and explanatory frameworks created around global indicators and the organisational priorities of transnational political initiatives? We argue, in the context of the articles published here, that anthropology's social justice goals may well sit uncomfortably within this contemporary moment of global health's evolution, which stresses populations over people and indicators over values and practices.

\section{The Academic Gaze}

Despite the important observations of Craig Calhoun (2008a, 2008b) and Didier Fassin (2015) that anthropology's orientation as generally taught and practised today affirms an academic turn that results 
in the sedimentation of a distanced academic gaze that transforms field-based interlocutors and experiences into 'the people we study', their work also offers alternatives. Amongst these is the idea that the people we study assume identities and connections to place, to other people and to globally circulating ideas. Julie Livingston (2012), for instance, has shown how global imaginaries of Africa and poverty have shaped the sicknesses that global health both pays attention to and ignores. Such hermeneutic work may help motivate production of studies that can shape alternative ways of seeing and of linking together and thinking with and about these people and their illnesses, as well as positive ways of constituting health. Similarly, in this special issue, we take the position that anthropology embedded in the broader global health project matters precisely because it attempts to push back against the academic gaze as a privileged method for knowledge creation.

We work from the premise that an academic gaze abstracts observable characteristics to conform to and affirm already extant ways of constituting, analysing and predicting outcomes of pre-identified problems, a process which has limited value (Pinney 2005). In other words, an academic gaze functions primarily to 'see' in a new place or circumstance what has already been seen elsewhere. The circumstances that lead to poor health amongst mothers in rural India may overlap with those that do so in Guatemala, but knowing whether they actually do begins not with indicators but with people as exemplars of complex social practices.

Anthropology, as a research tool deployed within multi-disciplinary projects, often moves researchers and research users to identify and find value in circumstances, data contexts and data constructs they might otherwise (wish to) ignore. In one important sense, this occurs by challenging researchers to question settled categories of knowledge or research design, sometimes even after a study has begun. Inclusion of anthropologists on global health research teams may influence or shape research design and conceptual shifts; other times, research teams choose not to recognise or take up such suggestions. David Mosse (2006), for instance, has written compellingly about how consensus decision-making in development contexts may silence different views. The people who make up typical global health multi-disciplinary research teams may take unexpected or contrary analyses and comments negatively and as a challenge. Yet, study methods and designs do change after research has begun in response to field circumstances and research team priorities, and this happens with greater and lesser degrees of hassle, delay and expense. How this happens depends on research team composition and the value that the team places on anthropological contribution (which sometimes gets labelled and conceptualised as a qualitative dimension of a study rather than an anthropological contribution).

Friction and questions invariably arise when researchers from other disciplines on research teams profess not to know what anthropology contributes, reduce anthropology to solely interviewing, or sideline possible contributions because of a disagreement about the 'rigour' of anthropology's methods (Nelson, this issue). As a colleague who works in a supportive global health research unit recounted, funders may have little if any awareness of what anthropologists hired onto projects do and contribute. Their presence may be locally valued, but publicly hidden. Other times, studies may include no 'deliverables' for ethnographic contributions. Severing anthropological work from research outputs may strategically allow anthropological investigators longer periods of freer and more flexible research, but it also means that funders and other research team members may not view this work as offering much, if any, public or policy value. Such strategies also may delay the career progression of anthropologists who work in global health, since they and their colleagues may have fewer expectations about valuing their work through publishing it.

Growing recognition within global health that knowing why people do things matters as much as knowing what they do has created the opportunity for broadly conceptualised qualitative research to contribute to global health (Van Belle, this issue). While anthropology may inform qualitative research as conceived and practised within global health, the two are not congruent. Typically, qualitative research in global health has meant 'do some interviews' or 'run some focus groups'. In some cases, there is a nod to wishing a research project could do more extensive or different kinds of qualitative work, but budgets, timetables, primary investigators' priorities, and clumsy execution may create insurmountable constraints.

A discussion with anthropologists who work in multi-disciplinary global health institutes confirmed a common bind. Invited to collaborate on research proposals or projects to develop a qualitative component, anthropologists may look for ways to make the project more intellectually, theoretically or critically appealing beyond responding to the core research questions through pre-determined, interview-based methods. But without sufficient time (be it for field- 
work, analysis or writing) or resources allocated to complete these tasks and to resolve the complexity they bring, researchers may find themselves with a 10-50 percent designated salary for a project that calls for in-depth reflection while other academic commitments demand their time. The call for 'slow research' (Adams et al. 2014) is ever more important in a time when existing professional structures can make such research seem even more of an impossibility.

Anthropology becomes problematic within such health research environments to the degree that the methods of the discipline make salient the kinds of potentially marginalising practices described above (as well as others not explicitly recounted here, such as reducing a set of fuller qualitative methods to only verbal and textual analysis). Even when offering careful and valuable accounts of research subjects' experiences with interventions and policies, anthropologists we speak to and work with seem concerned about how we all fit within today's global health driven by metrics, development paradigms that focus on what people do not have rather than on what they do, and biomedical/epidemiological interpretations of health. How, then, can we as anthropologists working in global health research contexts successfully produce knowledge about health (and sickness) while enabling, acknowledging and valuing fundamental humanness as an epistemological advantage, rather than as something to minimise, sideline, characterise as unreliable, or simply ignore? Two contrasting examples drawn from nutrition interventions illustrate and introduce more fully the concerns that this special issue will address.

\section{Qualitative Methods and Diminished Anthropology?}

A colleague recently lamented to us the poor quality of the qualitative data that she received for analysis as part of an ongoing project that seeks to improve children's nutrition outcomes in a sub-Saharan African country. Researchers contracted locally conducted interviews with inhabitants in two local indigenous languages. These interviews supplemented and intended to inform and contextualise quantitative survey data collected by another group within the research team. The qualitative researchers asked previously validated questions in the target languages and audio recorded the answers. Later, they, along with other locally contracted researchers, who had not been involved in the interview process, produced translations from the indigenous language into French to create a written transcript. Another group of researchers in another country - not professional translators - then translated the French transcript into an English-language document and presented it to my colleague in a third country along with the original indigenous language audio recordings for analysis.

No one on the analysis team had competence in the indigenous languages, and no one in the setting where the data had been originally collected had attempted to verify the quality of the translations from one language to the other. Ultimately, the analysis team understandably decided to dismiss this data as unreliable, though where it confirmed quantitative findings they presented it as qualitative evidence. Consequently, whatever the local population wanted to share about their health from their perspective ended up being ignored and actively silenced.

This research describes a shift from the broader toolkit of anthropological methods to the more focused qualitative methodology of targeted interviews. Our colleague had advocated for hiring anthropologists (or sociologists) to conduct research in parallel to quantitative data collection, but the principal investigator could not see the need and approved qualitative interviews as a concession. Poor research like this can occur with any methodological approach, even when funded by an international non-governmental organisation with an eight-figure budget - as in this case.

But, what matters in this example? Aside from the loss of potential knowledge, poorly executed qualitative research reinforces both the unfamiliarity of such approaches to data collection and analysis as well as potentially confirms biases about its subjective unreliability. Even though the principal investigator in this case approved a qualitative component, uncertainty about its benefit made him reluctant to hire experienced social scientists to lead it, though the budget could have accommodated it. So, it fell to the lead researcher on the ground to direct qualitative data collection, even though she had no training or experience to do so. Not only had this research not provided space for anthropological (or sociological) input, it so undervalued qualitative data and associated methodologies that it allowed someone without any training to lead this segment of the project.

We include this example because discussion amongst ourselves and with colleagues has led us to conclude that sometimes non-social-science global health colleagues collapse anthropological and qualitative contributions into a single category and that poor techniques and oversight, a collection of disjointed methods as opposed to sound underlying prin- 
ciples that demand reflection, and limited resources and follow-through characterise what we do. Having championed qualitative inclusiveness, which others executed poorly, made it harder for our colleague to fight for the incorporation of further and more in-depth qualitative research in their study. After all, she had already urged spending resources in a way that had brought little research value. Ultimately, the principal investigators hardened their stance against the future use of methodologies that they perceived as having probable 'low reliability'. They attributed fault to the method rather than to its execution, since, as our colleague said, it confirmed what they had already thought about qualitative methods and they lumped anthropology in with their assessment.

Through its sample size and quantitative execution, the larger research project produced usable numbers for the funders, we were told. However, by dismissing the bulk of qualitative work, it ultimately undermined the opportunity for indigenous people to appear in the study and to contribute their voices to it though the intervention intended to improve their lives. Critically, while the study offered local people the chance to participate in the research, because of inscrutable and clumsy translations it also made people who wished to be known linguistically knowable only statistically and as indicators of nutritional lack. What they have and what they do, rather than what they do not, the study chose to obscure and yet this satisfied the research protocol and the funders' criteria. Ultimately, the research reinforced the presumed need for international intervention, as well as for imported research and resources in part because the research as executed failed to identify what resources local people describe themselves as possessing and requiring.

We draw on another nutrition intervention for contrast. In this case, the research team diligently utilised a food security vulnerability tool with a target population to measure baseline and endline differences over the course of their intervention. They sought to describe and analyse coping strategies employed by people in refugee camps to deal with food insufficiency. The research questionnaire asked about decreased consumption of preferred foods, food borrowing practices, reduction of meal frequency, portions, and rationing strategies to make more food available for children. The results showed that the targeted population used all of these. Endline results indicated that the intervention had apparently succeeded in shifting the frequency with which the population utilised their coping strategies. But when questioned about which foods people preferred, the researchers, who had not included an anthropological or even a qualitative research component in their study, admitted that they had no idea.

The intervention took place across a growing season and used four-week recall to collect data. When we asked how researchers could know whether preferred foods were always available or whether they varied by season - which would attribute the change that their research identified as a possible response to seasonal food availability - they had no good answer. Probing food-borrowing practices elicited similar responses. The researchers did not know who the majority female-headed households borrowed food from, and did not know what kinds of foods they would borrow or even whether food borrowing and lending is desirable as a hedge against future need. They knew nothing about which adults in a household might reduce meal frequency or who may do so in favour of whom, except in the most general sense namely, that food flows from adults to children.

The conceptual problem that sits at the centre of the above intervention asks: what minimum conditions would eliminate the need for food-insecure populations to employ coping strategies? However, framing the research premise in this way assumes that people's coping strategies respond primarily to food scarcity; but what if they do not (Trapp 2016)? While interview-based qualitative work might well affirm the presumption that they do, anthropology would minimally ask about which specific strategies respond to and emerge from deeply integrating social practices. How families, groups, clans, communities and settlement configurations link to one another across time and via affective needs and aspirations matters for our discipline. These presumptions lead to the need to distinguish between a strategy that responds primarily to a slowly evolving food emergency and one that exists to affirm social identities and identifications that assume critical importance during food shortages (Trapp 2016).

\section{Glocal Attentiveness}

Locals may not act with resourcefulness and agency congruent with how researchers perceive their circumstances, which in turn drives research design and ideas about what people lack. But as João Biehl and Adriana Petryna note, precisely because '[p]eople constantly exceed the projections of experts' (2013: 5) our human-centred research must attend to the often structural constraints that impede locals' capability to achieve the ends that matter for them. As Paul 
Farmer and colleagues argued in the webpages of The Lancet (2013b), '[s]tripping away context, both local and translocal, creates the illusion of equipoise in a world riven by poverty and social disparities. ... All aspects of the research - from prioritising research questions to interpretation and dissemination of results - must have local involvement and promote a sense of ownership'.

And yet, 'glocal' attentiveness imposes on researchers the need to show how policy decisions in one country could not only produce unexpected and unintended consequences in another, but may also place direct structural change out of reach for locals in other parts of the world. When policy- and advocacy-oriented research uninformed by global ethnographic engagement frames local issues in ways that fail to conceptualise the interconnected, global and human dimensions of 'matters of concern' (Latour 2004), it imperils global health. As Livingston recounts (2018), automobile emissions standards in Japan simultaneously repress secondary markets for used cars nationally while generating secondary markets internationally in developing countries, which ultimately leads to more cars on the roads and increased road traffic fatalities outside of Japan.

Though anthropology comes burdened with its own set of abstractions and theoretical constructs that can mystify what, how and why people know things and do what they do, the anthropological project ostensibly begins and ends with the human being. What implications arise for global health knowledge if global health fails to incorporate the methods and practices through which its constituent disciplines and practitioners evidence what they know? John Locke long ago in 1689 explored this problem in $A n$ Essay Concerning Human Understanding (Locke 1975). As he put it, nothing prevents a blind man from working to common cause with another who sees, but on what basis should either person accept the other's declarations about the existence or experiences of sight and colour as true?

One way forward would require compromise, subsuming one claim to the other, or alternatively, agreeing principles (i.e. creating a model) that could well contradict what one party regards as certain and irrefutable facts. Imposing conditions on models, or empowering one claim to regnance over the other in global health often turns on mundane realities such as who controls the budget, who has highest rank, team composition, and so on. The same kinds of political, economic and sociological layers that Mark Nichter (2008) points to as critical for global health's general programmatic approach would also seem to shape the discipline's capacity to generate fundamental knowledge.

Of course, another possibility exists. The 'blind and sighted' amongst us strike no compromise. No translation of experience and evidence into a common language occurs. Each chooses ignorance or 'not knowing', stubbornly affirming their own ways of producing knowledge. Murray Last (1981) long ago explored 'not knowing' as a knowledge practice. By briefly discussing not knowing below, we wish to engage with the problem of selection bias as an epistemological and ontological question that impedes anthropology's potential integration into broader global health practice.

\section{Revising 'Not Knowing'}

'Not knowing' holds open the necessity of employing the unique and specific as the basis of analysis rather than defining such characteristics as outliers. In this way, 'not knowing' allows researchers to embrace the underlying political motivations for the work they do, even when such perspectives might be weakly or vaguely expressed as a desire to 'help people' or 'to make the world better'. In this sense, sharing a sandwich with someone who has not eaten, thus enabling them to take HIV medication and to participate in a behavioural study about drug efficacy (Prince 2012), responds both to local circumstances and political (self-)identity constructs. Ruth Prince's analysis also nakedly shows how a specific kind of academic knowledge, that privileged by medical interventions in the instance she describes, systematically elects not to know in order to produce knowledge in terms already acceptable for academic norms.

Not knowing features significantly in the evaluation of asylum claims (Fassin and D'Halluin 2005; Kohli 2005) and organ donation (Cohen 2003; Rose 2010), for example. Clinical trials may choose not to measure interim outcomes in order to avoid ethical obligations to provide treatment or to obscure recruitment practices (Joseph and Dohan 2012) that would reinforce the authority of the method. We can easily pile up examples. Research colleagues in India recounted how they had calculated body mass index (BMI) by measuring the waist circumferences and heights of a group of men as part of a health intervention. When they subsequently sought permission to share the results with the people who had given their data, health officials denied the request. Health surveys in the region had previously collected and reported BMI that officials had accepted and dissemi- 
nated even though they regarded the numbers as wildly inaccurate. To avoid controversy and possible embarrassment, they preferred to restrict access to the new numbers, since they might contradict previously disseminated facts utilised for policymaking.

Resonant with Prince's concerns above, Ulrich Beck (2006) argued for the ambiguity of risk. Beck noted that risks and related threats proliferate as a consequence of attending only to those risks for which programmes of identification and control already exist. This form of problem closure looks to the past to inform future action and ultimately seeks to extend the past into the future. Beck observed that the strategy of looking backwards manifests as poor identification of and preparedness for actual present threats. Beck recognised that vulnerability or 'risk as threat' arises precisely because of how a society refuses to know.

A generation before Beck, historian and medical anthropologist Murray Last (1981) published his analysis of the changing Hausa medical system under the title 'The Importance of Knowing about Not Knowing'. Last described the erosion of traditional medical knowledge with the introduction of hospital and clinic-based medical practices. The presence of these new institutions within the community led to the disintegration of systematised healing and curing as locally practised. As a direct result, secrecy proliferated amongst healers about the methods and treatments they employed. The people who had relied on community-based practitioners responded, perhaps defensively, with ambivalence to the new secrecy. They no longer wanted to know about their diagnoses or suggested remedies. Not knowing and not wanting to know became fundamental characteristics of the community. However, while choosing not to know and not to disclose in no way impeded the functioning of healing and curing practices undertaken outside of clinical settings, such practices disappeared as a knowable and heritable cultural resource.

Wenzel Geissler (2013) describes the pervasiveness of 'knowing not to know' in scientific and programmatic work. Building on Last, Geissler describes the practice of interpreting research findings so that they will fit almost congruently with accepted, dominant and already authorised knowledge. This approach to 'unknowing' masks inconveniences in scientific research and ascribes a hierarchy to knowledge, excluding what supposedly does not matter and so does not become known or disseminated.

In her work on evidence production and the circulation of knowledge, Emilia Sanabria (2016) argues that the constellation of public and expert debates overemphasises the risk of individual behaviour without permitting contrasting evidence and narratives. In her fieldsite, wilful ignorance, choosing not to know and choosing to exclude (potential) knowledge, may serve a variety of social and political purposes. Anthropology could offer a way out of the dominant evaluation tropes typical for this domain, as 'making noncausal and nonlinear relations visible is something that the practice of ethnography is uniquely equipped to do' (Sanabria 2016: 153).

Global health integrates overlapping, but different social imaginaries, even if it exists more as a collection of problems rather than as a discipline (Farmer et al. 2013). How research that comprises global health knowledge collaborates with political and administrative processes to nudge people towards certain behaviours and away from others matters (Varanda and Théophile, this issue). As Nichter (2008) points out, ranking, judging and intervening within human populations encompass many of the activities, strategies and outcomes that arise from the implementation of medical and global health programmes, and these often fall (uncomfortably) under anthropology's critical ethnographic engagement with knowledge practices.

\section{The Articles in this Special Issue}

The articles in this Special Issue ask how doing anthropology in the global health domain raises questions about anthropology's value to global health, and ask us to consider how that value arises in practice. Erica Nelson, a historian with applied and academic research experience utilising oral history and ethnography to analyse health systems in Latin America and globally, reflects in "I'm Not that Kind of Doctor': On Being In-Between in a Global Health Intervention' on her experiences as 'the qualitative researcher' for an adolescent sexual and reproductive health (ASRH) intervention in Latin America. Observing what she perceived as scepticism on the part of her colleagues with respect to how they responded to both her role in the project and her methods, her article explores issues of positionality and identity in relation to the generation of evidence in global health programmes. Bringing together themes of pregnancy, new motherhood and fieldwork, her work shows how 'unwittingly' distance between researcher and researched can collapse and so subtly shape observations. Despite the challenges, Nelson argues that research scenarios such as hers offer a role for anthropologists to disrupt common global health knowledge practices. 
Diane Duclos and colleagues' article, 'Envisioning, Evaluating and Co-Enacting Performance in Global Health Interventions: Ethnographic Insights from Senegal', explores the conceptualisation of how human actors influence access to medicines and the implications of how we manage drug access systems. Using ethnography as an analytical tool, the authors describe the often-neglected human component of inventory control in a reproductive health intervention. They argue that ethnography contributes to successful global health evaluations by identifying how dual practices of performance could lead to differing decisions about what causes inventory stock-outs. Anthropologists who undertake evaluations of global health programmes themselves perform ethnography and by doing so productively challenge existing global health norms. This research underlines the imperative for reflexivity in the shifting field of global health.

History of medicine scholar and medical anthropologist Jorge Varanda and his colleague Josenando Théophile draw on nearly two decades of personal engagement with sleeping sickness and a century of documentation in their article 'Putting Anthropology into Global Health: A Century of Anti-Human African Trypanosomiasis Campaigns in Angola'. They remind us of the positive and negative legacies of colonial and international health projects and how these have shaped contemporary global health ideas and practices for addressing infectious diseases. The authors demonstrate that certain health problems need epidemiological, historical and anthropological responses and so make a compelling case for why anthropology must influence health interventions.

Sara Van Belle takes up the relevance of anthropological approaches and methods for clinical, quantitative, systems-oriented researchers in global health in her article, 'Global Health Research, Anthropology and Realist Enquiry: Methodological Musings'. Van Belle explores commonalities and differences across two research paradigms in global health: one, longstanding, about medical anthropology and ethnographic research, and the other about realist enquiry. She examines realist enquiry as a response that quantitative researchers have developed to address the perceived need for qualitative rigour that anthropology cannot apparently provide while recognising the limits of trials and other quantitative measures for explaining complex health problems.

In the final contribution, Murray Last reflects on his 50-year anthropological career amongst the Hausa in northern Nigeria. By describing what he asked, what he wanted to know and how he navigated his identity in the community where he lived as a guest, he offers a sense of the proximity and distance of the global health project for rural villages and of the limits of anthropological and ethnographic knowledge. Last's thoughtful article takes up 'not knowing' from a radically different perspective. Building on the critical distinction between 'public health' and 'the public's health', he describes recognising, exploring and interpreting knowledge constructs over time. $\mathrm{He}$ asks whether anthropological knowledge might go out of date, even as the anthropologist seeks to continually renew what she or he knows through informal learning and engagement with fieldwork environments. The social opportunities provided by long-term fieldsites respond to global contexts as well as to internal and external pressures. They change and so shift the opportunities available to the anthropologist to generate current ethnography precisely because of how the anthropologist generates what she or he knows.

\section{Conclusion}

Anthropologists learn to frame problems in ways that allow critical analyses to arise because using anthropological methodologies will confer advantage for problem analysis and evidence description. But how should one discipline amongst many negotiate the authority to claim that privilege within the everyday practices of global health? How we define global health matters less than how we constitute global health, which means that how we describe problems to allow collaborating disciplines opportunities to shape problem analyses and evidence descriptions matters in its own right. To do otherwise betrays the capability of our discipline to recognise and value the diversity of the world(s) within which we live.

Robert Chambers and Ian Carruthers's (1981) important critiques about how the anthropological discipline's insistence on long-term fieldwork pushed anthropology to the sidelines within development contexts resonate with the body of work presented in this Special Issue. Even though possessed of relevant information about and experience of places in the world engaged in development projects, anthropological insights emerged too slowly to be relevant to work that needed outcomes in months rather than in years. Putting his critiques into practice, Chambers developed and applied participatory methods that could be deployed quickly in environs characterised by poor literacy. In contrast to Chambers, many anthropologists who work in global health settle for strategic 'not knowing' and have chosen to solely utilise various 
forms of structured verbal data elicitation. They essentially ignore many of the theoretical and interactive techniques bequeathed by anthropology's long history to accommodate the expectations of colleagues, fit within budgets and timetables, and adhere to other apparently necessary constraints. The question emerges: how does one give priority to people over data, when social imaginaries and attendant practices identify the people and their environments as threats?

Anthropology produces and draws on a different evidence base from other disciplines contributing to global health. As long as anthropologists are willing to compromise on how its evidence is viewed in order to be acceptable to other disciplines, we will never get anywhere and only reinvent the same types of problems and debates. Anthropological analysis can - if it is so inclined - capture or describe multiple perspectives and illustrate through analysis how incongruence arises between those positions and, importantly, why that incongruence matters. This is the challenge of anthropology in global health: to show why incongruence matters, instead of masking or obscuring it. This is what anthropology does well, and we aspire to see it integrated, valued and given space in global health research.

Talal Asad (1994) argues that qualitative experiences and research in such a world aligned with a global health social imaginary may be strategically positioned to test how thoroughly the values associated with the imaginaries of quantitative methodologies and statistics have been embodied by local populations and inform their social practices. We understand part of Asad's project as revealing the degree to which knowledge systems of the Other have taken root in local communities. Asad's observations resonate with the realisation of Berger's doctor quoted above, if not the latter's anxiety for how he might inappropriately shape and influence those he lives amongst and to whom he offers practical help. Berger's masterpiece reveals the interior life of a doctor whose practice changes him. What is the global health equivalent? What could change, as it were, global health's interior life and open it to ethnographic and anthropological practice more fully?

Rodney Reynolds is a teaching fellow in anthropology and global health at the Institute for Global Health, University College London (UCL). His research interests surround conceptualisations of nutrition, health and obesity. His fieldwork in Mexico on this topic has been supported by the Newton Fund. Email: rodney.reynolds@ucl.ac.uk
IsABELLE LANGE is a research fellow in anthropology at the London School of Hygiene and Tropical Medicine (LSHTM) in the Department of Global Health and Development and the Department of Infectious Disease Epidemiology.

Email: isabelle.lange@lshtm.ac.uk

\section{References}

Adams, V. (2013), 'Evidence-Based Global Public Health: Subjects, Profits, Erasures', in J. Biehl and A. Petryna (eds.), When People Come First: Critical Studies in Global Health (Princeton, NJ: Princeton University Press), 54-90.

Adams, V., N. J. Burke and I. Whitmarsh, (2014), 'Slow Research: Thoughts for a Movement in Global Health', Medical Anthropology 33, no. 3: 179197. doi:10.1080/01459740.2013.858335.

Asad, T. (1994), 'Ethnographic Representation, Statistics and Modern Power', Social Research 61, no. 1: 55-88. http://www.jstor.org/stable/40971022.

Beck, U. (2006), 'Living in the World Risk Society: A Hobhouse Memorial Public Lecture Given on Wednesday 15 February 2006 at the London School of Economics', Economy and Society 35, no. 3: 329345. doi:10.1080/03085140600844902.

Berger, J. and J. Mohr (1967), A Fortunate Man: The Story of a Country Doctor (London: Allen Lane).

Biehl, J. and A. Petryna, (2013), When People Come First (Princeton, NJ: Princeton University Press).

Calhoun, C. (2008a), 'Social Science for Public Knowledge' In: Eliaeson, Sven and Kalleberg, Ragnvald, (eds.) Academics as Public Intellectuals. Cambridge Scholars Publishing, Newcastle, UK, pp. 299-318. ISBN 9781847184764

Calhoun, C. (2008b), 'Cosmopolitanism in the Modern Social Imaginary', Daedalus 137, no. 3: 105-114. doi:10.1162/daed.2008.137.3.105.

Chambers, R. and I. Carruthers (1981), 'Rapid Appraisal for Rural Development', Agricultural Administration 8, no. 6: 407-422. doi:10.1016/ 0309-586X(81)90036-4.

Cohen, L. (2003), 'Where It Hurts: Indian Material for an Ethics of Organ Transplantation', Zygon 38, no. 3: 663-688. doi:10.1111/1467-9744.00527.

Davis, C. (2018), 'Closing Plenary Lecture', presented at the Valuing Health Conference 2018, University of Edinburgh, Scotland, 4-5 September.

Erikson, S. L. (2012), 'Global Health Business: The Production and Performativity of Statistics in Sierra Leone and Germany', Medical Anthropology 31, no. 4: 367-384. doi:10.1080/01459740.2011.621908. 
Evans-Pritchard, E. E. (1946), 'Applied Anthropology', Africa 16, no. 2: 92-98.

Farmer, P. (2003), Pathologies of Power: Health, Human Rights and the New War on the Poor (Berkeley: University of California Press).

Farmer, P., A. Kleinman, J. Kim and M. Basilico (eds.) (2013a), Reimagining Global Health (Berkeley: University of California Press).

Farmer, P., M. Murray and B. Hedt-Gauthier (2013b), 'Clinical Trials and Global Health Equity', The Lancet Global Health Blog, 8 July, http://globalhealth.thelan cet.com/2013/07/08/clinical-trials-and-global-healthequity.

Fassin, D. (2015), 'The Public Afterlife of Ethnography', American Ethnologist 42, no. 4: 592-609. doi:10.1111/ amet.12158.

Fassin, D. and E. D'Halluin (2005), 'The Truth from the Body: Medical Certificates as Ultimate Evidence for Asylum Seekers', American Anthropologist 107, no. 4: 597-608. doi:10.1525/aa.2005.107.4.597.

Geissler, P. W. (2013), 'Public Secrets in Public Health: Knowing Not to Know while Making Scientific Knowledge', American Ethnologist 40, no. 1: 13-34. doi:10.1111/amet.12002.

Janes, C. and K. Corbett (2010), 'Anthropology and Global Health', in B. J. Good, M. M. Fischer, S. S. Willen and M. J. D. Good (eds.), A Reader in Medical Anthropology: Theoretical Trajectories, Emergent Realities (Chichester, UK: John Wiley \& Sons), 405-421.

Joseph, G. and D. Dohan (2012), 'Recruitment Practices and the Politics of Inclusion in Cancer Clinical Trials', Medical Anthropology Quarterly 26, no. 3: 338-360. doi:10.1111/j.1548-1387.2012.01222.x.

Kleinman, A. (2010), 'Four Social Theories for Global Health', Lancet 375, no. 9725: 1518-1519. doi:10.1016/ S0140-6736(10)60646-0.

Kohli, R. K. (2005), 'The Sound of Silence: Listening to What Unaccompanied Asylum-Seeking Children Say and Do Not Say', British Journal of Social Work 36, no. 5: 707-721. doi:10.1093/bjsw/bch305.

Last, M. (1981), 'The Importance of Knowing about Not Knowing', Social Science \& Medicine. Part B: Medical Anthropology 15, no. 3: 387-392. doi:10.1016/ 0160-7987(81)90064-8.

Latour, B. (2004). 'Why Has Critique Run out of Steam? From Matters of Fact to Matters of Concern', Critical Inquiry 30, no. 2: 225-248. doi:10.1086/421123.

Livingston, J. (2012), Improvising Medicine: An African Oncology Ward in an Emerging Cancer Epidemic (Durham, NC: Duke University Press).

Livingston, J. (2018), 'Keynote', presented at the Valuing Health Conference 2018, University of Edinburgh, Scotland, 4-5 September.
Locke, J. [1689] (1975), An Essay Concerning Human Understanding: Edited with an Introduction, Critical Apparatus and Glossary by Peter H. Nidditch (Oxford: Clarendon Press).

Marcus, G. E. and D. Cushman (1982), 'Ethnographies as Texts', Annual Review of Anthropology 11: 25-69.

Merry, S. E. and J. M. Conley (2011), 'Measuring the World: Indicators, Human Rights, and Global Governance', Current Anthropology 52, no. S3: S83-S95. doi:10.1086/657241.

Mosse, D. (2006), 'Anti-Social Anthropology? Objectivity, Objection, and the Ethnography of Public Policy and Professional Communities', Journal of the Royal Anthropological Institute 12, no. 4: 935-956. doi:10.1111/j.1467-9655.2006.00371.x.

Nader, L. (2011), 'Ethnography as Theory', Journal of Ethnographic Theory 1, no. 1: 211-219. doi.org/10 .14318/hau1.1.008.

Nguyen, V. K. (2016), 'Anthropology and Global Health', in Ted Schrecker (ed.), The Ashgate Research Companion to the Globalization of Health (New York: Routledge), 101-118.

Nichter, M. (2008), Global Health: Why Cultural Perceptions, Social Representations, and Biopolitics Matter (Tucson: University of Arizona Press).

Pinney, C. (2005), 'Things Happen: Or, From Which Moment Does that Object Come?', in D. Miller (ed.), Materiality (Durham, NC: Duke University Press), 256-272.

Prince, R. (2012), 'HIV and the Moral Economy of Survival in an East African City', Medical Anthropology Quarterly 26, no. 4: 534-556. doi:10.1111/maq.12006.

Prince, R. J. and R. Marsland (eds.) (2014), Making and Unmaking Public Health in Africa: Ethnographic and Historical Perspectives (Athens: Ohio University Press).

Rose, D. A. (2010), Larry's Kidney: Being the True Story of How I Found Myself in China with My Black Sheep Cousin and His Mail-Order Bride, Skirting the Law to Get Him a Transplant - and Save His Life (New York: William Morrow).

Sanabria, E. (2016), ‘Circulating Ignorance: Complexity and Agnogenesis in the Obesity "Epidemic"', Cultural Anthropology 31, no. 1: 131-158. doi:10.14506/ ca31.1.07.

Storeng, K. T. and D. P. Béhague (2017), ““Guilty Until Proven Innocent": The Contested Use of Maternal Mortality Indicators in Global Health', Critical Public Health 27, no. 2: 163-176. doi:10.1080/09581596.2016 .1259459 .

Trapp, M. M. (2016), 'You-Will-Kill-Me-Beans: Taste and the Politics of Necessity in Humanitarian Aid', Cultural Anthropology 31, no. 3: 412-437. doi:10.14506/ca31.3.08. 